\title{
COVID-19 Süreci ve Fizyoterapide Telerehabilitasyon Uygulamaları:
}

\section{Derleme}

\section{COVID-19 Process and Telerehabilitation Applications in Physiotherapy: Review}

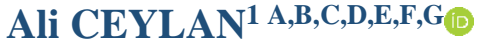 \\ ${ }^{1}$ Karamanoğlu Mehmetbey Üniversitesi, Sağl1k Hizmetleri Meslek Yüksekokulu, Terapi ve Rehabilitasyon Bölümü, \\ Karaman, Türkiye
}

ÖZ

\begin{abstract}
2019 Aralık ayının son günlerinde Çin'de nedeni açıklanamayan ve solunum yollarında ciddi harabiyete neden olan bir hastalık tespit edilmiş ve Dünya Sağlık Örgütü tarafindan hastalığa COVID-19 adı verilmiştir. COVID-19 hastalığı sadece enfekte olanları değil, karantina uygulamaları nedeniyle evlerinde kalan her kesimden insanı fiziksel ve psikolojik yönden olumsuz etkilemiştir. Sağlık hizmeti veren kuruluşlarda yoğunluk yaşanmasına ve sağlık hizmetlerinin sunumunda güçlüklerin yaşanmasına neden olmuştur. Bu nedenle COVID-19 hastalığı; telesağlık/ tele-tıp veya telerehabilitasyon gibi web tabanlı uygulamalara olan ilgiyi artırmıştır. Fizyoterapistler, tedavi sırasında hastalarıyla yakın temas içerisinde uygulamalarını gerçekleştirdikleri için enfeksiyon açısından riskli meslek grubundadır. Böyle bir dönemde araştırmacılar fizyoterapistlerin acil durumlar dışında tedavilerine ara vermeleri gerektiğini, zorunlu tedavilerde ise enfeksiyon kurallarına uyumun önemli olduğunu bildirmiştir. Ayrıca bilim insanları tarafından enfeksiyon yayılım hızını azaltabileceği düşüncesiyle telerehabilitasyon uygulamalarının alternatif bir tedavi seçeneği olabileceği de belirtilmiştir. Telerehabilitasyon, teknoloji tabanlı bir dizi araçlar kullanarak fizyoterapistler tarafından bireylerin sağlığının geliştirilmesi için rehabilitasyon hizmetlerinin uzaktan verilmesi olarak tanımlanmıştır. Fizyoterapistler, COVID-19 döneminde telerehabilitasyon ile sağlık hizmetlerini uzaktan sunarak bireylerin egzersizlerini gerçekleştirebilir, hastalarını değerlendirebilir ve enfeksiyon yayılım hızını azaltabilir. Araştırmalarda telerehabilitasyon hizmetlerinin geleneksel tedavi yöntemleri kadar etkili olduğunu, hastaların fonksiyonelliğini sağlamada ve ağrının azaltılmasında faydalı olabileceği belirtilmiştir. Ayrıca taburculuk sonrası rehabilitasyon uygulamalarının devamlılığını sağladığı da ifade edilmiştir. Bu yüzden salgın döneminde telerehabilitasyon uygulamalarının yaygınlaştırılması için sağlık çalışanları ile yeterli personel ve teknik alt yapının sağlandığı ortak bir platformda sağlık bakanlığına bağlı web tabanlı bir sistemin kazandırılması önem arz etmektedir. Daha geniş bir kitleyi içine alan kalıcı uygulamaların yaygınlaştııılması ile literatürde kısıtlı sayıda bulunan telerehabilitasyon çalışmalarının niteliğinin ve sayısının artabileceği düşüncesindeyiz.
\end{abstract}

Anahtar Kelimeler: COVID-19, Telerehabilitasyon, Teletıp, Fizyoterapist, Rehabilitasyon.

\section{ABSTRACT}

In late 2019, an unexplained disease was detected in China, causing severe respiratory damage, and the World Health Organization named the disease COVID-19. COVID-19 has negatively affected people from all walks of life who remain in their homes due to quarantine practices, not just those who are infected. It has led to an intensity in health care organizations and difficulties in the delivery of Health Services. Physical therapists are at risk for infection, as they practice in close contact with their patients during treatment. Researchers reported that physical therapists should decongest their treatment except in emergencies, and compliance with infection rules is important in mandatory treatments. In addition, telerehabilitation applications have been recommended by scientists with the idea that it can reduce the rate of infection spread. Telerehabilitation has been defined by physiotherapists using a range of technology-based tools as remote provision of rehabilitation services to improve the health of individuals. Physiotherapists can perform individuals ' exercises, evaluate their patients and reduce the rate of infection spread by remotely offering health services with telerehabilitation during the COVID-19 period. Research has shown that telerehabilitation applications can be as effective as conventional treatment protocols. It is important to acquire a web-based system in which sufficient personnel and technical infrastructure are provided for the dissemination of telerehabilitation practices during the epidemic period. We believe that with the dissemination of permanent practices, the quality of telerehabilitation studies, which are found in a limited number of literature in our country, may increase.

Sorumlu Yazar: Ali CEYLAN

Karamanoğlu Mehmetbey Üniversitesi, Sağlık Hizmetleri Meslek Yüksekokulu, Terapi ve Rehabilitasyon Bölümü, Karaman, Türkiye aliceylan@kmu.edu.tr

Geliș Tarihi: 22.01.2021 - Kabul Tarihi: 25.05.2021

Yazar Katkıları: A) Fikir/Kavram, B) Tasarım, C) Veri Toplama ve/veya İşleme, D) Analiz ve/veya Yorum, E) Literatür

Taraması, F) Makale Yazımı, G) Eleştirel İnceleme 
Key Words: COVID-19, Telerehabilitation, Telemedicine, Physical Therapists, Rehabilitation.

\section{GíRiş}

2019 Aralık ayının sonlarına doğru Çin'in Hubei eyaleti Wuhan kentinde nedeni tam olarak açıklanamayan ve solunum yollarında ciddi harabiyete neden olan yeni bir hastalık tespit edilmiştir. İlk vaka bildirimlerinin ardından Dünya Sağlık Örgütü (DSÖ), hastalığı 7 Ocak 2020 tarihinde COVID-19 olarak isimlendirmiştir $(1,2)$. DSÖ, kısa süre içinde tüm dünyayı hızlı bir şekilde etkileyen COVID-19 hastalığını 11 Mart 2020 tarihinde salgın olarak kabul etmiştir (3). Ülkemizde de aynı tarihte görülen ilk vakanın hemen ardından sağlık otoriteleri tarafından topluma evde kalmaları yönünde çağrı yapılmış, sosyal izolasyonun önemini vurgulayan önlemlerden bahsedilmiştir (4). Hastalığın en yaygın semptomları arasında; ateş, öksürük, yorgunluk, kas ağrısı ve nefes darlığı yer alırken, Avrupa ülkelerinde gerçekleştirilen bir çalışmada en çok karşılaşılan semptomların sırasıyla; baş ağrısı, koku alamama, burun tıkanıklığı, yorgunluk, kas ağrısı, burun akıntısı, tat almada kayıp, boğaz ağrısı ve ateş olduğu görülmüştür $(5,6)$. Yapılan çalışmalar, ölüm oranlarının ileri yaş ve kronik hastalık (hipertansiyon, kardiyovasküler hastalık, diyabetes mellitus, kronik akciğer hastalığı, kanser vb) varlığında daha yüksek olduğunu göstermiştir $(7,8)$.

Tüm dünyada ciddi vaka sayılarıyla birlikte ölümlere neden olan COVID-19 hastalığı ile ilgili aşı çalışmaları yoğun bir şekilde devam ederken, tamamlanan çalışmaların aşı etkinlik sonuçları da ülkelerce paylaşılmaktadır. Böyle belirsiz bir ortamda virüsün davranışını yakından izleyen bilim insanları, COVID-19 salgınının ne zaman son bulacağı ile ilgili herhangi bir bilgiyi kamuoyu ile paylaşmamış, toplum tarafından salgının uzunca bir süre daha devam edebileceği düşüncesi yaygınlık kazanmaya başlamıştır. Salgının etkilerini azaltmak amacıyla ülkelerin almış olduğu lokal ve genel karantina uygulamaları, sağlık kurumlarında acil olmayan ameliyatların iptal edilmesi, hastanedeki birimlerin kapatılıp COVID-19 salgını kapsamında hizmet veren birimlere dönüştürülmesi, hastanelerin pandemi hastanesi olarak hizmet vermeye başlaması, hastanedeki yoğunluğu ve iş yükünü azaltmak için alınan önlemler gibi pek çok neden insanların sağlık hizmetlerini almalarında bir takım güçlükleri de beraberinde getirmiştir.

COVID-19 salgını sürecinde tanı alan ve almayan bireylerin izole edilmesi, salgının etkilerini azaltmak için alınan diğer önlemler fizyoterapiye ihtiyaç duyan bireylerin rehabilitasyon hizmeti almasını engellemiş ve ayrıca COVID-19 tanısı alan bireylerin bulaş açısından risk teşkil etmesi fizyoterapi uygulamalarının etkin bir şekilde uygulanamamasına neden olmuştur. Bu nedenle olağanüstü bir dönem olarak ifade edilen COVID-19 salgını sürecinde telerehabilitasyonun önemi çok daha iyi anlaşılmıştır (9). Yapılan araştırmalarda tedavisi tamamlanan hastaların ev egzersizlerine katılımı ve devam etmesinde problemler yaşadığı görülmektedir. Hastaların fizyoterapistler tarafından kişiye özgü verilen ev egzersizlerini yapmadığı ya da kısmen yaptığı belirlenmiştir (10). Bu derlemede; olağanüstü bir dönem olan salgın sürecinde, sağlı hizmetlerinin sürdürülebilirliğinde fizyoterapide telerehabilitasyon uygulamalarının önemini ortaya koymak amaçlanmıştır.

\section{Tele-tıpın alanı: Telerehabilitasyon}

Tele-tıp, geçmişi 30 yıl öncesine kadar uzanan ve uzun yıllardır literatürde yer alan bir konseptir. Tele-tıp; teknoloji kullanımı ile tedavinin uzaktan gerçekleştirilmesi prensibine 
dayanan uygulamaları içermektedir (11). Fizyoterapi alanında ise tele-tıp, telerehabilitasyon şeklinde karşılık bulmuş ve kısaca ' rehabilitasyon hizmetlerinin bilgi ve iletişim teknolojileri yoluyla sağlanması" "şeklinde ifade edilmiştir (12). Geniş anlamda telerehabilitasyon; bilgi ve iletişim teknolojileri gibi bir dizi araçlarla rehabilitasyon uzmanları tarafından hastalara bağımsızlık düzeylerinin geliştirilmesi amacıyla rehabilitasyon hizmetlerinin (izlem, müdahale, denetim, eğitim, danışmanlık vb) belirli prosedür ve protokoller aracılığıyla uzaktan verilmesi olarak tanımlanmaktadır (13-15).

Son yıllarda teknoloji alanında yaşanan gelişmeler, mobil cihaz tabanlı sağlık hizmetlerini ortaya çıkarmış, yüz yüze tedavi yöntemlerine alternatif ve maliyeti düşük bir rehabilitasyon seçeneği sunmuştur. Bu gibi pek çok avantajlara sahip olması sebebiyle telerehabilitasyon, araştırmacılara da farklı bir bakış kazandırmıştır $(14,16)$. Tele-tıp teknolojisi ile amaç; hastaneye başvuru oranının düşürülmesi, hekim vizit sayısının azaltılması, hastaların evinde takip edilmesi, rehabilitasyon hizmetlerinin uzaklara taşınması ve direkt olarak hastanın olduğu yerde sağlık hizmetlerinin verilmesi olarak belirlenmiştir (17).

\section{Avantajları}

Telerehabilitasyonun gelişmiş teknoloji, yeterli alt yapı ve iletişimin sağlanması durumunda uzaktan verilen sağlık hizmetlerine önemli katkıları olabileceği belirtilmektedir (18). Tele-sağlık/Telerehabilitasyon uygulamalarının avantajları şu şekilde belirtilebilir:

- Telerehabilitasyon; şehirden uzak, kırsal bölgelerde yaşayanların ve özellikle büyük yüz ölçümüne sahip ülkelerde periferde yaşayan toplumun sağlık hizmetlerine ulaşabilmesini kolaylaştırır. Böylece hizmetlerin sunulması ve kullanılmasında toplumda oluşan eşitsizliğin azaltılabileceği düşünülmektedir $(17,19)$.

- Herhangi bir hastalık veya sakatlığa bağlı olarak tedaviye ulaşamayan hastaların da tedaviye ulaşabilmelerine imkan tanır (17). Araştırmalar telerehabilitasyon uygulamalarının zaman ve sağlık harcamalarını azaltabileceğini, ekonomik olarak sağlık hizmetlerine erişim sağlayamayan hastaların rehabilitasyon hizmetlerinden yararlanabileceğini göstermiştir $(20,21)$.

- Hasta, hasta yakınları ve bakım sağlayan bireyler ile sağlık hizmeti veren birimler arasında tıbbi bilgi paylaşımlarına izin verir (22).

- Evde bakım biriminde çalışan bir fizyoterapistin eve gitme zorunluluğunu ortadan kaldıracağı için, zamandan elde edilen tasarruf ile bir günde daha fazla hastaya ulaşılabilmesine ve hizmet verilebilmesine olanak sağlar (9). COVID-19 salgını sirasında verilen telerehabilitasyon hizmetleri ile rehabilitasyon gereksinimi olan daha fazla sayıda hastaya ulaşıldığı bildirilmiştir (17).

- Özellikle günümüzde olduğu gibi salgın dönemlerinde rehabilitasyon merkezlerine gidilemediği ya da gitmenin riskli olduğu durumlarda yakın teması ortadan kaldırır, sosyal mesafe korunmuş olur (9).

- Dijital tabanlı verilen fizyoterapi uygulamaları, fizik tedavi hizmetlerinin etkin ve verimli bir şekilde sürdürülmesine ve topluma sunulmasına, fizyoterapistler tarafından bireylere verilen ev programlarının takibine yardımcı olur. $(3,23)$. 
- Hastaneye yatış oranlarını azaltabilir, yeni kabulleri önleyebilir. Hastaların erken taburcu olmasına ve ayakta tedavi, rehabilitasyon uygulamalarına anında erişim, hastaların yaşam kalitesinde iyileşmeler ve hastaların işe erken dönüşüne imkan tanıyabilir $(24,25)$.

\section{Dezavantajları}

Tele-sağlık/Telerehabilitasyon uygulamaları sağlık çalışanlarına sunduğu avantajlarının yanında, özellikle uygulanabilirlik ve sürdürülebilirlikte bir takım dezavantajları da vardır. Bunlar şu şekilde belirtilebilir:

- Fizyoterapi uygulamaları, gerektiğinde direkt olarak elle yapılan pek çok tedavi ve değerlendirme yöntemlerini içerir. Uzaktan erişimle verilen telerehabilitasyon hizmetleri, dokunmanın terapötik etkisini ortadan kaldıracağı için tedavide etkinliği azaltabilir (19).

- Uzaktan sağlık hizmeti veren sağlık birimleri ile hastalar arasında telerehabilitasyon sisteminin kurulmasında ve bu sistemlerde ortaya çıkabilecek olası problemlerin çözümünde yetersiz teknik bilgi ve donanım, sistemin verimini ve başarısını düşürebilir (23).

- Internet alt yapısı ile ilgili problemler, veri aktarımı ve hasta mahremiyetinin nasıl sağlanacağ

- Hastane ortamında ya da fizik tedavi ünitelerinde ekipmanla (elastik bant, ağırlık, terapi topu vb.) yapılan egzersiz uygulamaları telerehabilitasyon hizmetleri ile yapılamayabilir. $\mathrm{Bu}$ durum tedavinin terapötik etkisini azaltarak tedavi sonuçlarını etkileyebilir (25).

\section{COVID-19 sürecinde fizyoterapi ve telerehabilitasyon}

COVID-19 salgınının tüm dünyada ve ülkemizde hızlı yayılım göstermesi, fizyoterapi ve rehabilitasyon hizmetlerini de etkilemiş, fizik tedavi ünitesinde zorunlu aksamalara neden olmuştur $(3,26)$. Bu nedenle COVID-19 salgını, fizyoterapistlerle birlikte toplumu da teknoloji tabanlı fizyoterapi uygulamaları olan telerehabilitasyona yönlendirmiştir (27). Telerehabilitasyon, video-konferans sistemleri, sensör teknolojileri ve sanal gerçeklik gibi sistemler aracılığıyla gerçekleştirilebilmektedir (19). Kişiye temas olmadan verilen telerehabilitasyon hizmetleri ile hasta, bakım veren ve sağlık personeli arasındaki iletişimin kuvvetlenebileceği, COVID-19 dönemindeki telerehabilitasyon uygulamalarının salgının yayılım hızını azaltabileceği bildirilirken, telerehabilitasyonun çeşitli nedenlerle evde kalmak zorunda kalan bireyler için de alternatif bir seçenek olabileceği vurgusu yapılmıştır (3).

Fizyoterapistler meslekleri gereği hastalarla yakın temas içerisinde bulunarak tedavilerini gerçekleştirdikleri için COVID-19 salgınında risk altında yer alan meslek grubu olarak belirtilmektedir (28). Araştırmalarda, hasta ve hasta yakınlarının sağlı̆̆ının korunması ve COVID-19 yayılımının önüne geçilmesi amacıyla acil durumlar dışında fizyoterapistlerin tedavilerine ara vermeleri gerektiği vurgulanmış, acil durumlar için uygulanan tedaviler sırasında, enfeksiyondan korunmak için sağlık otoritelerince belirtilen talimatlara uyulması gerektiği ifade edilmiştir (29-31). Ayrıca enfeksiyon riskinin azaltılması, fizyoterapistler için daha güvenli ve etkin çalışma ortamlarının oluşturulabilmesi için fizyoterapiye ihtiyaç duyan 
hastalarda hastane içi dönemde de telerehabilitasyon uygulamalarının tercih edilebileceği tavsiye edilmiştir $(30,32)$.

Telerehabilitasyon; normal dönemde hastanede verilen rehabilitasyon hizmetlerine benzer bireysel görüşmeleri, hasta değerlendirmelerini, rehabilitasyon hedeflerini ve bireysel egzersizleri içermektedir (33). Fizyoterapistlerin kullanımı için telerehabilitasyon rehberi oluşturulmuş ve fizyoterapi eğitimine telerehabilitasyon dahil edilmiştir (33). Bu sayede fizyoterapistlere fayda sağlayan telerehabilitasyon, bireylerde kas iskelet sisteminde sürekliliği sağlama, hastaları doğrudan kendi ev ortamlarında uzaktan eğitme, bireye özgü fiziksel değerlendirme ve amaçlanan egzersizleri gerçekleştirme, planlama, hastaların sürecini değerlendirme firsatı sunarak geri bildirim ve denetim firsatı sunmaktadır. Belirlenen rehabilitasyon programlarının şiddeti, sıklığı ve süresi, kişinin yaşına ve ihtiyaçlarına göre belirlendiği ifade edilmiştir (24,25) Turollo ve ark. COVID-19 salgını sürecinde fizyoterapistlerin telerehabilitasyon ile tedavilerine devam edebileceklerini bildirilmiştir (31) (Şekil-1).

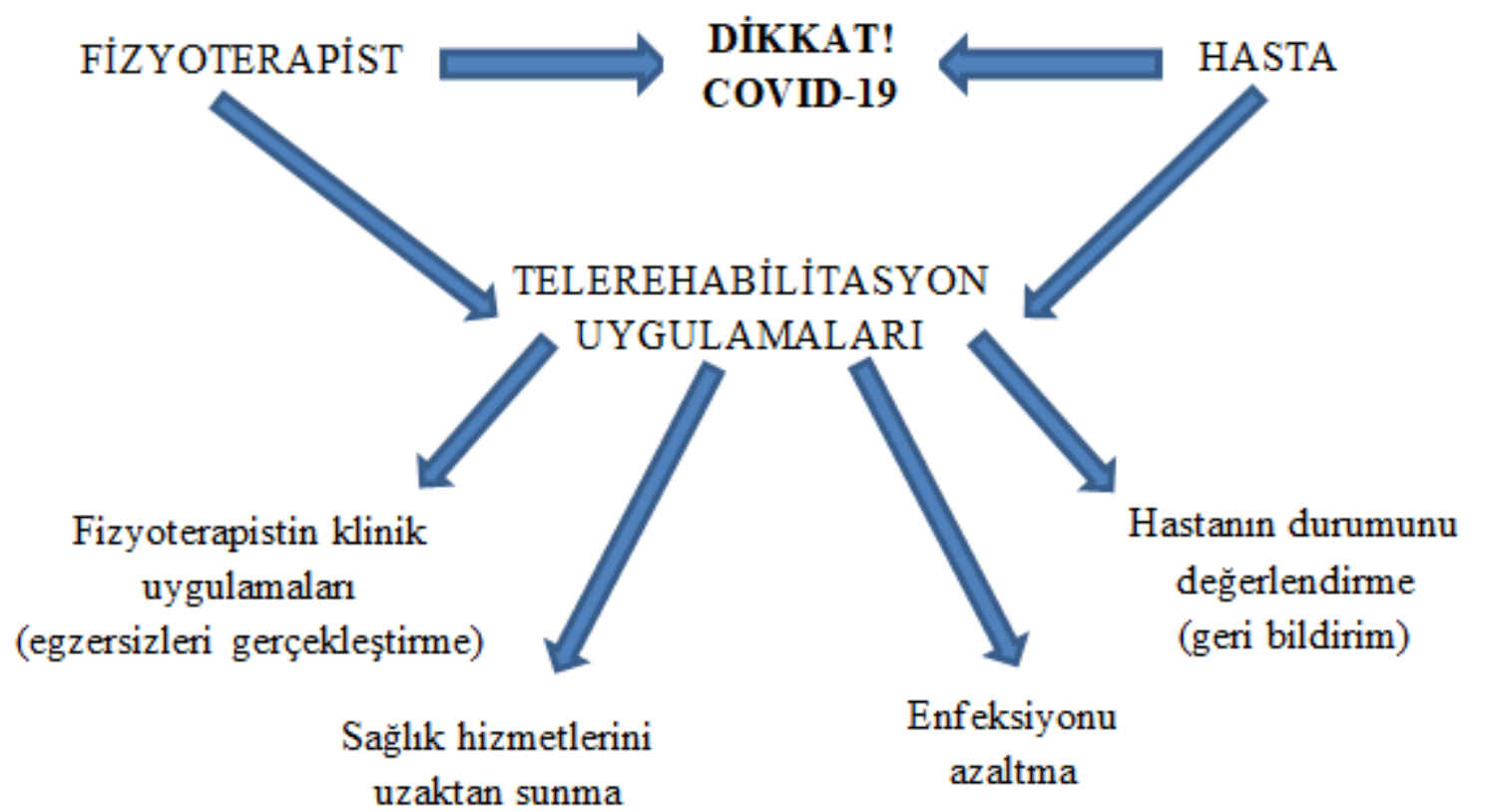

Şekil 1. COVID-19 Sürecinde Fizyoterapist-Hasta İlişskisi (31)

Literatürde salgın öncesi ve salgın sürecinde telerehabilitasyon çalışmalarına rastlamak mümkündür (Tablo 1). Telerehabilitasyon uygulamaları ile ilk makale 1998 yılında yayınlanmış, 2000'lere geldiğimizde artan bir ivme kazanmış ve günümüze kadar gelmiştir $(17,22)$. Ortopedik ve kas-iskelet sistemini ilgilendiren hastalıklarla ilgili son y1llarda yapilan çalışmalarda, telerehabilitasyon uygulamalarının konvensiyonel tedavi yöntemleri kadar etkili ve yeterli olabileceği belirtilmiştir (13). 6 Osteoartrit tanılı hastalar ile gerçekleştirilen egzersize devam, motivasyon ve diğer davranışsal faktörler gibi parametrelerin göz önünde bulundurulduğu bir çalışmada kullanıcının ihtiyacına göre düzenlenen teknoloji kullanımı ile verilen telerehabilitasyon uygulamalarının konvensiyonel uygulamalara göre üstünlüğünü açıklayabilecek sonuçların elde edildiği görülmüştür (35). 
Tablo 1. Telerehabilitasyon Çalışmaları ve Sonuçları

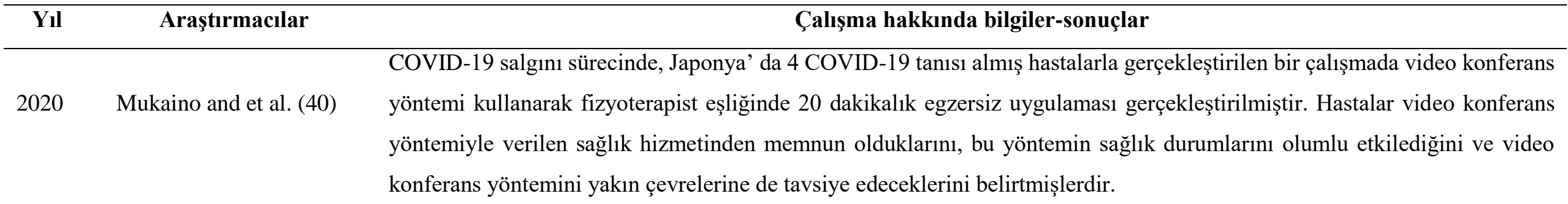

$2019 \quad$ Mbada and et al. (36)

Çalışmaya 47 mekanik bel ağrılı hasta dahil edilmiş ve katılımcılar Mckenzie tedavi grubu (n=26) ve telerehabilitasyon grubu $(n=21)$ olarak 2 gruba ayrılmıştır. Elde edilen sonuçlar gruplar arasında anlamlı bir farkın olmadığını bu nedenle video tabanlı gerçekleştirilen telerehabilitasyon uygulamalarının etkili bir sağlık hizmeti olabileceği ifade edilmiştir.

2018 Danbjørg and et al. (35). uygulamalarının konvensiyonel uygulamalara göre daha üstün olabileceği sonucuna varılmıştır.

$2017 \quad$ Cottrell and et al. (37)

Sistematik inceleme ve meta-analizi olarak planlanmış araştırmada 13 çalışma gözden geçirilmiş, kas iskelet sistemi hastalıklarının tedavisinde gerçekleştirilen telerehabilitasyon uygulamalarının hastalarda fonksiyonelliği sağlamada ve ağrının azaltılmasında etkili olabileceği bildirilmiştir.

İnmeli hastalarda telerehabilitasyonun etkinliğine bakılan pilot çalışmada 15 kişi 3 hafta süreyle 9 seanslık telerahabilitasyon

2017 Hüzmeli ve ark. (15) uygulamasına alınmış tedavi sonrası hastalarda dengenin geliştiği belirlenmiştir.

2017 y1lında gerçekleştirilen sistematik derlemede 15 çalışma incelenmiş, telerehabilitasyonun total diz ve kalça artroplastisi

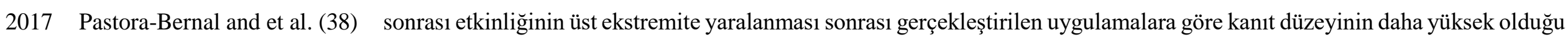
görülmüştür.

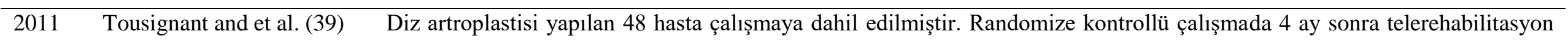
grubunda yapılan uygulamaların geleneksel rehabilitasyon uygulamaları kadar etkili olabileceği ifade edilmiştir. 
Mekanik bel ağrılı 47 katılımcının dahil olduğu randomize kontrollü bir çalışmada video tabanlı egzersiz grubu ile klinik temelli Mckenzie tedavi grubu karşılaştırılmış ve iki grup arasında tedavinin etkinliğinde anlamlı bir farkın olmadığı belirtilmiş, telerehabilitasyonun etkili bir teknoloji tabanlı sağlı hizmeti olduğu ifade edilmiştir (36). 2017 yılında gerçekleştirilen sistematik inceleme ve meta-analizinde 13 çalışma gözden geçirilmiş, kas iskelet sistemi hastalıklarının tedavisinde gerçekleştirilen telerehabilitasyon uygulamalarının sağlık hizmetlerine erişimin kısıtlı olduğu durumlarda telefon veya video konferans gibi tekniklerle verilmesinin hastalarda fonksiyonelliği sağlamada ve ağrının azaltılmasında etkili olabileceği bildirilmiştir (37). İnmeli hastalarda telerehabilitasyonun etkinliğine bakılan pilot çalışmada 15 kişi 3 hafta süreyle 9 seanslık telerahabilitasyon uygulamasına alınmış tedavi sonrası hastaların dengesinin geliştiği, fakat mental durum ile yaşam kalitelerinde tedavi öncesine göre fark olmadığı belirlenmiştir (15). 2017 yılında 15 çalışmanın sonuçları ile oluşturulan sistematik derlemede telerehabilitasyon uygulamalarınn etkinliğine bakılmış, total diz ve kalça artroplasti hastalarında telerehabilitasyonun etkinliğinin güçlü, üst ekstremite yaralanmalarında ise kanıt düzeyinin orta-zayıf olduğu belirtilmiştir (38). Diz artroplastisi geçirmiş 48 hastanın dahil edildiği bir çalışmada bir gruba geleneksel tedavi diğer gruba ise telerehabilitasyon hizmeti verilmiştir. 4 ay sonunda elde edilen sonuçlarda her iki grupta da gelişim gözlemlenmiş, telerehabilitasyonun geleneksel rehabilitasyon kadar etkili olabileceği ortaya konmuştur (39). COVID-19 salgını sürecinde, Japonya' da dört COVID-19 tanısı almış hastalarla gerçekleştirilen bir çalışmada video konferans yöntemi kullanarak fizyoterapist eşliğinde verilen 20 dakikalık egzersiz uygulaması gerçekleştirilmiştir. Hastalar video konferans yöntemiyle verilen sağlık hizmetinden memnun olduklarını, bu yöntemin sağlık durumlarını olumlu etkilediğini ve video konferans yöntemini yakın çevrelerine de tavsiye edeceklerini belirtmişlerdir (40). Araştırmalar fizyoterapistler tarafından hastanın yaşına ve durumuna göre verilen egzersizlerin, video ara yüzü ile hastalara gönderilmesinin ve uzaktan takibinin gerçekleştirilebilmesini mümkün kıldığını göstermektedir (41). COVID-19 sürecindeki karantina uygulamaları özellikle ciddi hastalıkları olan yaşlılarda, anksiyete ve depresyonun artmasına neden olmaktadır. Fiziksel aktivitenin karantina ile kısıtlanmış olması fiziksel ve psikolojik iyilik halini azaltabileceği de belirtilmektedir (33). Bu sebeple salgın sürecinde teknoloji tabanlı çeşitli görsel materyaller ve videolar ile verilecek telerehabilitasyon uygulamaları sadece hastalara değil, enfeksiyon yayılımını azaltmak amacıyla uygulanan ev kısıtlamalarından etkilenen bireylerin sağlığının devamı ve rehabilitasyon hizmetlerine ulaşabilmesi için de önemlidir $(3,33)$.

\section{SONUÇ}

Küresel anlamda COVID-19 salgını, yaşamımızda bazı değişiklikler ve alışkanlıklar edinmemizin yanı sıra, özel veya kamu alanında sunulan hizmetlerin uygulanmasında da önemli değişikliklere neden olmuştur. Uzmanların olağanüstü bir dönem olarak adlandırdıkları COVID-19 salgını, tüm dünyada sağlık hizmetlerinde aksaklıklara neden olmuştur. Ülkeler toplum sağlığının ve sağlık hizmetlerinin devamlılığı için çeşitli çözüm arayışlarına yönelmiştir. Salgını durdurmak için aşı çalışmalarına hızla devam edilirken sağlık hizmetlerinin sürdürülebilirliği için sağlık otoriteleri salgın döneminde telerehabilitasyon uygulamalarını kullanmayı önermiştir. Yapılan araştırmalar COVID-19 salgın sürecinde teknoloji tabanlı 
sağlık hizmetlerinin sunumunda artış olduğunu göstermiştir (42). Tele-sağlık, yüz yüze sağlık hizmetine ulaşamayan bireyler için oldukça etkili ve uygulanabilir bir yöntemdir. Şu an için COVID-19 döneminde sağlık hizmetlerine erişimdeki boşluğu doldurmuş gibi görünse de, COVID-19 salgını sonrasında da tele-sağlık hizmetlerinin devam edebileceği tahmin edilmektedir. $\mathrm{Bu}$ sebepledir ki tele-sağl1k geçici bir yöntem olarak düşünülmemeli, sürdürülebilir alternatif bir uygulama olarak değerlendirilmelidir (43). Yapılan araştırmalarda, tele-sağlık ve telerehabilitasyon uygulamalarının konvensiyonel uygulamalar kadar etkin ve geçerli olduğu belirtilmiştir (13, 35-37). Fizyoterapistlerin olağan günlerde uygulayacakları telerehabilitasyon hizmetleri ile daha fazla sayıda bireye rehabilitasyon hizmetlerinin ulaştırılabileceği vurgulanmıştır. Ayrıca COVID-19 salgını döneminde fizyoterapistlerin sağlık otoritelerince telerehabilitasyon hizmeti vermesi önerilmiştir $(30,32)$. Fizyoterapistin ve hastanın sağlığı güvence altına alınarak enfeksiyon riskinin azaltılması hedeflenmiştir (29-31). Bu kapsamda ülkemizde de telerehabilitasyon uygulamalarının yaygınlaştırılması için gerekli altyapı ve teknik personelin sağlanması, hazırlanan ara yüzlerin kullanımları ile ilgili eğitimlerin verilmesi, telerehabilitasyon hizmetlerinde kalıcılığın sağlanması için yapılacak çalışmaların önemli olabileceği kanısındayız. Telerehabilitasyon uygulamalarının yaygınlaştırılması ile ülkemizde de literatürde kısıtlı sayıda bulunan çalışmaların niteliğinin ve sayısının artabileceği düşüncesindeyiz. Telerehabilitasyon uygulamalarının dezavantajlarının ortadan kaldırılarak uzun vadede daha kapsamlı ve birçok kesimin kullanabileceği ve yararlanabileceği yeni bir sistem üzerinde planlama yapılabilir.

COVID-19 salgını, sadece enfekte olan hastaları değil, salgının yayılım hızını azaltmak amaciyla uygulanan karantina nedeniyle evlerinde kalmak zorunda kalan her kesimden insanı fiziksel ve psikolojik yönden olumsuz etkilediği ortadır (33). Bu kapsamda enfekte olmayan bireylerin de sağlığının korunması için telerehabilitasyon uygulamalarının, olağanüstü bir dönem olarak ifade edilen salgın sürecinde daha fazla kullanımı sağlanmalıdır. Hastalık yoktur hasta vardır ilkesinden hareketle fizyoterapist tarafından gerçekleştirilen değerlendirmeler sonrası, bireye özgü verilen rehabilitasyon programlarının web tabanlı teknoloji (görüntülü video konferans, akıllı telefon uygulamaları vb.) vasıtasıyla hastaya ulaştırılmasının sağlık hizmetlerinin devamlılığına katkı sağlayabilir. Tele-sağlık hizmetlerinin yaygınlaştırılması için sağlık çalışanları ile yeterli personel ve teknik alt yapının sağlandığı ortak bir platformda sağlık bakanlığına bağlı web tabanlı bir sistemin kazandırılması oldukça önemlidir. Sağlık hizmetlerinin sunumundaki eşitsizliği azaltmak, rehabilitasyon sürecini yoğunlaştırmak ve tedavi sonrası da sürekliliği sağlamak amacıyla yaşamın her döneminde telerehabilitasyonun kolay erişilebilir ve aktif kullanılan bir platform olması gerektiği düşüncesindeyiz.

\section{Çıkar Çatışması}

Bu çalışmada yazarların çıkar çatışması durumları yoktur.

\section{KAYNAKLAR}

1. Zhu, N., Zhang, D., Wang, W., Li, X., Yang, B. Song, J. et al. (2020). A novel coronavirus from patients with pneumonia in China. The New England Journal of Medicine, 382(8), 727-733. 
2. Altın, Z. (2020). Covid-19 Pandemisinde Yaşlılar. Tepecik Ĕgitim ve Araştırma Hastanesi Dergisi, 30 (Ek say1), 49-57.

3. Dündar Ahi, E., Ayhan, F.F., \& Demirbağ Kabayel, D. (2020). COVID-19 ve fiziksel tıp ve rehabilitasyon. İçinde: Ayhan, F.F., Demirbağ Kabayel, D. (editörler). COVID19 Pandemisi ve Fiziksel Tip ve Rehabilitasyon. p.1-6, Ankara (Türkiye): Türkiye Klinikleri.

4. COVID-19 (sARs-CoV-2 Enfeksiyonu) Rehberi (Bilim Kurulu Çalışması). (2020). Erişim: https://covid19bilgi.saglik.gov.tr/depo/rehberler/COVID-19_Rehberi.pdf

5. Huang, C., Wang, Y., Li, X., Ren, L., Zhao, J., Hu, Y. et al. (2020). Clinical features of patients infected with 2019 novel coronavirus in Wuhan, China. Lancet, 395(10223), 497-506.

6. Leichen, H. R., Chiesa-Estomba, C. M., Place, S., Van Laethem, Y., Cabaraux, P., Mat, Q. et al. (2020). Clinical and epidemiological characteristics of 1,420 European patients with mild-to-moderate coronavirus disease. Journal of Internal Medicine, 288(3), 335344.

7. Zhou, F., Yu, T., Du, R., Fan, G., Liu, Y., Liu, Z. et al. (2020). Clinical course and risk factors for mortality of adult inpatients with COVID-19 in Wuhan, China: a retrospective cohort study. Lancet, 395(10229), 1054-1062.

8. Wu, C., Chen, X., Cai, Y., Xia, J., Zhou, X., Xu, S. et al. (2020). Risk factors associated with acute respiratory distress syndrome and death in patients with coronavirus disease 2019 pneumonia in Wuhan, China. JAMA Internal Medicine, 180(7), 1-11.

9. Kahraman, T. (2020). Koronavirüs hastalı̆̆1 (COVID-19) pandemisi ve telerehabilitasyon. İzmir Kâtip Çelebi Üniversitesi Sağllk Bilimleri Fakültesi Dergisi, 5(2), 87-92.

10. Dean, S. G., Smith, J., Payne, S., \& Weinman J. (2005). Managing time: an interpretative phenomenological analysis of patients' and physiotherapists' perceptions of adherence to therapeutic exercise for low back pain. Disability \& Rehabilitation, 27(11), 625-636.

11. Flodgren, G., Rachas, A., Farmer, A.J., Inzitari, M., \& Shepperd, S. (2015). Interactive telemedicine: effects on professional practice and health care outcomes. Cochrane Database of Systematic Reviews, 2015(9), CD002098.

12. Brennan, D., Tindall, L., Theodoros, D., Brown, J., Campbell, M., Christiana, D. et al. (2010). A blueprint for telerehabilitation guidelines. International Journal of Telerehabilitation, 2(2), 31-34.

13. Özden, F., Arık, F. A., \& Tuğay, N. (2020). Ortopedik fizyoterapi alanında güncel telerehabilitasyon yaklaşımları. Türkiye Klinikleri Sağlık Bilimleri Dergisi, 5(2), 354360 .

14. Gilbert, A. W., Jaggi, A., \& May, C. R. (2018). What is the patient acceptability of real time 1:1 videoconferencing in an orthopaedics setting? A systematic review. Physiotherapy, 104(2), 178-186.

15. Hüzmeli, E. D., Duman, T., \& Y1ldırım, H. (2017). Türkiye'de inmeli hastalarda telerehabilitasyonun etkinliği: pilot çalışma. Turk Nöroloji Dergisi, 23(1), 21-25.

16. Moral-Munoz, J. A., Zhang, W., Cobo, M. J., Herrera-Viedma, E., \& Kaber, D.B. (2019). Smartphone-based systems for physical rehabilitation applications: a systematic review. Assistive Technology, 21, 1-14.

17. Kesiktaş, F. N., \& Bilir Kaya, B. (2020). Telerehabilitasyon. İçinde: Ayhan, F.F., \& Demirbağ Kabayel, D., (editörler) COVID-19 Pandemisi ve Fiziksel Tip ve Rehabilitasyon. p.89-93, Ankara (Türkiye): Türkiye Klinikleri.

18. Torsney, K. (2003). Advantages and disadvantages of tele-rehabilitation for persons with neurological disabilities. NeuroRehabilitation, 18(2),183-185. 
19. Russell, T. G. (2009). Telerehabilitation: a coming of age. Australian Jorunal of Physiotherapy, 55(1), 5-6.

20. Hailey, D., Roine, R., Ohinmaa, A., \& Dennet, L. (2011). Evidence of benefit from telerehabilitation in routine care: a systematic review. Journal of Telemedicine and Telecare, 17(6), 281-287.

21. Rogante, M., Grigioni, M., Cordella, D., \& Giacomozzi, C. (2020). Ten years of telerehabilitation: A literature overview of technologies and clinical applications. NeuroRehabilitation, 27(4), 287-304.

22. Burns, R. B., Crislip, D., Daviou, P., Temkin, A., Vesmarovich, S., Anshutz, J. et al. (1998). Using tele-rehabilitation to support assistive technology. Assistive Technology, 10(2), 126-133.

23. Richmond, T., Peterson, C., Cason, J., Billings, M., Abrahante Terrel, E., Chong W Lee, A. et al. (2017). American telemedicine association's principles for delivering telerehabilitation services. International Jornal of Telerehabilitation, 9(2),63-68.

24. Galea, M. D. (2019). Telemedicine in rehabilitation. Physical Medicine and Rehabilitation Clinics of North America, 30(2),473-483.

25. Howard, I. M., \& Kaufman, M. S. (2018). Telehealth applications for outpatients with neuromuscular or musculoskeletal disorders. Muscle Nerve, 58(4), 475-485.

26. Çağlar Yağcı, H., \& Bağcıer, F. (2020). COVID-19 sonrası fizik tedavi ve rehabilitasyon hizmetleri. İçinde: Ayhan, F.F., \& Demirbağ Kabayel, D. (editörler). COVID19 Pandemisi ve Fiziksel Tip ve Rehabilitasyon. p. 94-98, Ankara (Türkiye): Türkiye Klinikleri.

27. Van Houswelingen, C. T., Moerman, A. H., Ettema, R. G., Kort, H. S., \& Ten Cate, O. (2016). Competencies required for nursing telehealth activities: a Delphi-study. Nurse Education Today, 39, 50-62.

28. Burdorf, A., Porru, F., \& Rugulies, R. (2020). The COVID-19 (Coronavirus) pandemic: consequences for occupational health. Scandinavian Journal of Work, Environment \& Health, 46(3), 229-230.

29. Boldrini, P., Bernetti, A., Fiore, P., \& Simfer, E. C. (2020). Impact of COVID-19 outbreak on rehabilitation services and Physical and Rehabilitation Medicine (PRM) physicians' activities in Italy. An official document of the Italian PRM Society (SIMFER). European Journal of Physical and Rehabilitation Medicine, 56(3),316-318.

30. İnal İnce, D., Vardar Yağlı, N., Sağlam, M., \& Çalık Kütükcü, E. (2020). Yeni tip koronavirüs (Sars-Cov-2) kaynaklı COVID-19 enfeksiyonunda akut dönem ve postakut dönemde fizyoterapi ve rehabilitasyon. Türk Fizyoterapi ve Rehabilitasyon Dergisi, 31(1), 81-93.

31. Turolla, A., Rossettini, G., Viceconti, A., Palese, A., \& Geri, T. (2020). Musculoskeletal Physical Therapy During the COVID-19 Pandemic: Is Telerehabilitation the Answer?. Physical Therapy, 100(8), 1260-1264.

32. Ceravolo, M. G., De Sire, A., Andrenelli, E., Negrini, F., \& Negrini, S. (2020). Systematic rapid "living" review on rehabilitation needs due to COVID-19: update to march 31st 2020. European Journal of Physical and Rehabilitation Medicine, 56(3), 347-353.

33. Purssell, E., Gould, D., \& Chudleigh, J. (2020). Impact of isolation on hospitalised patients who are infectious: systematic review with meta-analysis. BMJ Open, 10(2), e030371.

34. Lee, A. C. (2020). COVID-19 and the Advancement of Digital Physical Therapist Practice and Telehealth. Physical Therapy, 100(7), 1054-1057.

35. Danbjørg, D. B., Villadsen, A., Gill, E., Rothmann, M. J., \& Clemensen J. (2018). Usage of an exercise app in the care for people with osteoarthritis: userdriven exploratory 
study. JMIR Mhealth Uhealth. 6(1), e11.

36. Mbada, C. E., Olaoye, M. I., Dada, O. O., Ayanniyi, O., Johnson, O. E., Odole, A. C. et al. (2019). Comparative efficacy of clinic-based and telerehabilitation application of McKenzie therapy in chronic low-back pain. International Journal of Telerehabilitation, 11(1),41-58.

37. Cottrell, M. A., Galea, O. A., O’Leary, S. P., Hill, A. J., \& Russell, T. G. (2017). Realtime telerehabilitation for the treatment of musculoskeletal conditions is effective and comparable to standard practice: a systematic review and meta-analysis. Clinical Rehabilitation, 31(5),625-38.

38. Pastora-Bernal, J. M., Martin-Valero R, Baron-Lopez F. J., \& Estebanez-Perez M. J. (2017). Evidence of benefit of telerehabitation after orthopedic surgery: A systematic review, J Med Internet Res. 28,19(4):e142.

39. Tousignant, M., Moffet, H., Boissy, P., Corriveau, H., Cabana, F., Marquis, F. (2011). A randomized controlled trial of home telerehabilitation for post-knee arthroplasty, $J$ Telemed Telecare, 17(4), 195-198.

40. Mukaino, M., Tatemoto, T., Kumazawa, N., Tanabe, S., Kato, M., Saitoh, E. et al. (2020). Staying active in isolation: Telerehabilitation for individuals with the SARSCoV-2 infection. American Journal of Physical Medicine \& Rehabilitation, 99(6), 478479.

41. Kemp, J. L., Coburn, S. L., Jones, D. M., \& Crossley, K. M. (2018). The physiotherapy for Femoroacetabular Impingement Rehabilitation STudy (physioFIRST): a pilot randomized controlled trial. Journal of Orthopaedic \& Sports Physical Therapy, 48(4), 307-315.

42. Laddu, D. R., Lavie, C. J., Phillips, S. A., \& Arena, R. (2020). Physical activity for immunity protection: Inoculating populations with healthy living medicine in preparation for the next pandemic. Progress In Cardiovascular Diseases, doi: 10.1016/j.pcad.2020.04.006.

43. Cottrell, M. A., \& Russel, T. G. (2020). Telehealth for musculoskeletal physiotherapy. Musculoskeletal Science and Practice, 48, 102193. 